\title{
Ekploitasi Tubuh Perempuan dalam Iklan Mobil Hyundai Santa Fe di Youtube
}

\author{
Monica Teppy Waworuntu', Ahmad Junaidi²* \\ ${ }^{1}$ Fakultas Ilmu Komunikasi, Universitas Tarumanagara, Jakarta \\ Email: monica.915170051@stu.untar.ac.id \\ ${ }^{2}$ Fakultas Ilmu Komunikasi, Universitas Tarumanagara, Jakarta* \\ Email: ahmadd@fikom.untar.ac.id
}

Masuk tanggal : 15-12-2021, revisi tanggal : 06-01-2022, diterima untuk diterbitkan tanggal : 16-01-2022

\begin{abstract}
Technology and communication continues to develop following the times. Many people spread creativity by giving birth to things that have artistic meaning. One of them is through advertisements that are presented to the wider community in both paper and video form. The Hyundai Santa Fe advertisement is an example of how an advertisement depicts a woman who can create perceptions or stereotypes. The hypodermic needle theory was an early concept of the mass communication effect. This theory assumes that the communication component has a very big influence in changing the attitudes and behavior of the audience. This study used a qualitative research approach. The subjects in this study were women in the Hyundai Santa Fe advertisement. The research object is the Hyundai Santa Fe advertising video on Youtube social media. This research shows that the female figure in the advertisement displays the sensuality and sexiness side of her attraction to a car. There are hidden signs in the advertisement, namely women's facial expressions that symbolize passion and can lead to various perceptions and stereotypes and exploitative.
\end{abstract}

Keywords: advertisement, exploitation, stereotype, woman

\begin{abstract}
Abstrak
Seiring dengan berjalannya waktu, teknologi dan komunikasi terus berkembang mengikuti perkembangan zaman. Banyak orang menyebarkan kreativitas dengan melahirkan hal-hal yang memiliki makna artistik. Salah satunya melalui iklan yang disajikan kepada masyarakat luas baik dalam bentuk kertas maupun video. Iklan Hyundai Santa Fe merupakan contoh bagaimana sebuah iklan menggambarkan sosok perempuan yang dapat menimbulkan persepsi atau stereotip. Teori jarum hipodermik adalah konsep awal dari efek komunikasi massa. Teori tersebut mengasumsikan bahwa komponen komunikasi memiliki pengaruh yang sangat besar dalam mengubah sikap dan perilaku khalayak. Pada penelitian ini digunakan pendekatan penelitian kualitatif. Subyek dalam penelitian ini adalah perempuan dalam iklan Hyundai Santa Fe. Obyek penelitian adalah video iklan Hyundai Santa Fe pada media sosial Youtube. Penelitian ini menunjukkan bahwa stereotipe sosok perempuan dalam iklan menampilkan sisi sensualitas dan keseksian dalam ketertarikannya dengan sebuah mobil. Terdapat tanda - tanda tersembunyi di dalam iklan tersebut, yaitu ekspresi wajah perempuan yang melambangkan gairah dan menggambarkan stereotipe perempuan dan cenderung eksploitatif.
\end{abstract}

Kata kunci: ekploitasi, iklan, perempuan, stereotipe

\section{Pendahuluan}

Iklan atau periklanan adalah segala bentuk presentasi non pribadi dan promosi gagasan, barang atau jasa oleh sponsor tertentu yang harus dibayar (Kotler, 2007:244). 
Pada prinsipnya iklan memungkinkan para pengiklan untuk mengkomunikasikan pesan krusial pada sekelompok aktar atau konsumen atau khalayak menggunakan media lebih cepat daripada bentuk komunikasi lainnya. Dalam teori jarum hipodermik dijelaskan bahwa komponen komunikasi (komunikator, pesan, \& media) mempunyai efek atau imbas yang pada perilaku khalayak (Rahmawati, 2020).

Sebuah iklan merupakan salah satu cara bagi pengiklan untuk mempromosikan barang atau jasa yang ada. Iklan bergerak dengan cara mempersuasi audiens untuk melihat bahkan melakukan pembelian barang atau jasa yang ditawarkan (Susanto, 2014). Sebuah iklan mampu mendeskripsikan sosok perempuan sedemikianrupa yang mampu menciptakan persepsi atau yang dianggap stereotip (Chang, 2006). Meneurut Kamus Besar Bahasa Indonesia, stereotip adalah konsepsi mengenai sikap suatu golongan yang didasarkan pada prasangka subyektif. Sosok perempuan yang ditampilkan menggunakan pakaian seksi atau memamerkan lekuk tubuh yang bisa menyebabkan persepsi audiens yang berbeda-beda. Steretip tubuh ideal perempuan dapat dipersepsikan sama dengan iklan tersebut yang di sampaikan melalui sebuah media dalam hal ini media sosial Youtube (Faiqah, 2016). Penggambaran stereotipe perempuan dalam sebuah iklan dapat juga dipandang sebagai eksplotasi perempuan (Wicaksono, 2012). Iklan mobil SantaFe akhirnya dicabut oleh Hyundai karena banyak menuai protes (detik.com, 2020). Namun iklan tersebut masih dapat dilihat di Youtube karena diunggah oleh akun lain.

Penelitian ini ingin mengetahui bagaimana steretip perempuan digambarkan dalam iklan pada sebuah iklan otomotif dalam iklan Hyundai Santa Fe? dan bagaimana sebuah iklan mampu membangun stereotipe terhadap perempuan? Penelitian ini diharapkan bisa membantu menambah wawasan dan manfaat pengetahuan bagi peneliti terkait terpaan pesan dan perspektif terhadap sebuah iklan.

\section{Metode Penelitian}

Penelitian ini menggunakan pendekatan kualtatif (Anggito, 2018, Maleong 2017) dengan metode semiotika. Dalam penelitian ini penulis memakai semiotika Roland Barthes (Marifah, 2020, Pratiwi 2015). Data merupakan hasil pencatatan peneliti, baik berupa fakta ataupun angka yang dapat dipakai untuk menyusun informasi dalam suatu keperluan. Peneliti menggunakan data primer dan sekunder. Data primer yaitu data yang dikumpulkan penulis berdasarkan sumber pertama atau langsung. Data ini diambil berdasarkan cuplikan - cuplikan video dalam iklan Hyundai Santa Fe. Data sekunder merupakan data pendukung atau tambahan untuk mendukung penelitian. Sumber data sekunder ini berupa jurnal ilmiah, artikel - artikel, situs internet, juga buku - buku yang berkaitan menggunakan representasi perempuan.

Metode pengumpulan data yang dipakai pada penelitian ini adalah observasi (Hasanah, 2017). Observasi dilakukan dengan melihat video iklan dalam situs Youtube dan menonton tayangan iklan Hyundai Santa Fe yang terdapat dalam salah satu channel Youtube. Peneliti juga menggunakan metode dokumentasi dengan mencari informasi melalui catatan, buku, surat kabar, notulen, rencana dan sebagainya. Dokumentasi pada penelitian ini akan dilakukan menggunakan menyertakan foto foto cuplikan berdasarkan tayangan video iklan Hyundai Santa Fe.

Analisis data merupakan kegiatan mengorganisasi, mengelompokkan, mengkategorikan, mengkodekan / menandai dan dikategorikan untuk memperoleh temuan menurut fokus masalah yang akan dipecahkan. Penguraian data ini menggunakan menganalisis cuplikan video iklan yang sebagai tanda pada iklan 
Monica Teppy Waworuntu, Ahmad Junaidi: Ekploitasi Tubuh Perempuan dalam Iklan Mobil Hyundai Santa Fe di Youtube

Hyundai Santa Fe tersebut. Gambar 1 merupakan peta tanda pola 3 dimensi berdasarkan Roland Barthes.

Gambar 1. Peta Tanda Roland Barthes

\begin{tabular}{|l|l|}
\hline $\begin{array}{l}\text { 1. Signifier } \\
\text { (Penanda) }\end{array}$ & $\begin{array}{l}\text { 2. Signified } \\
\text { (Petanda) }\end{array}$ \\
\cline { 1 - 2 } $\begin{array}{l}\text { 3. Denotatif Sign } \\
\text { (Tanda Denotatif) }\end{array}$ & \\
\hline $\begin{array}{l}\text { 4. Connotative Signifier (Penanda } \\
\text { Konotatif) }\end{array}$ & $\begin{array}{l}\text { 5. Connotative Signified (Petanda } \\
\text { Konotatif) }\end{array}$ \\
\hline 6. Connotative Sign (Tanda Konotatif) \\
\hline
\end{tabular}

Sumber: Observasi Peneliti

Gambar 1 menunjukkan bahwa perindikasi denotasi (3) yaitu stereotipe yang terjadi pada video iklan Hyundai Santa Fe terdiri atas penanda (1) yang merupakan video iklan Hyundai Santa Fe dan petanda (2) yaitu sosok perempuan pada iklan Hyundai Santa Fe. Pada waktu yang sama, indikasi denotasi juga adalah penanda konotasi (4) yaitu sosok perempuan yang menampakan kesensualitasannya pada beberapa adegan atau scene yang masih ada pada video iklan tersebut.

Teknik keabsahan data yang dipakai dalam penelitian ini merupakan teknik triangulasi. Triangulasi dalam hakikatnya adalah pendekatan multi metode yang dilakukan peneliti dalam waktu mengumpulkan dan menganalisis data. Oleh karenanya teknik ini adalah bisnis pengecekan kebenaran data atau keterangan yang diperoleh dari aneka macam sudut pandang yang tidak sama menggunakan mengurangi sebesar mungkin bias dalam waktu pengumpulan dan analisis data. Untuk itu dipakai teknik triangulasi asal data, yaitu menggali kebenaran informasi eksklusif melalui aneka macam metode dan asal perolehan data. Triangulasi asal data ini memakai observasi, dokumen tertulis, catatan resmi, wawancara, catatan atau goresan pena langsung dan gambar ataupun foto. Masing - masing cara ini akan menaruh pandangan yang berbeda yang bisa sebagai acuan atau pendukung bagi penelitian tentang kenyataan yang diteliti.

\section{Hasil Temuan dan Diskusi}

\section{Stereotifikasi Perempuan dalam Iklan Hyundai Santa Fe}

Iklan Hyundai Santa Fe merupakan iklan yang menjadi sebuah bentuk promosi mobil Hyundai SUV terbaru pada tahun mobil ini dikeluarkan. Penelitian ini berfokus pada aspek tanda untuk menjawab rumusan permasalahan penelitian ini yaitu representasi dan stereotifikasi terhadap perempuan dalam iklan Hyundai Santa Fe yang terdapat pada beberapa scene dalam iklan tersebut, seperti pada scene I berikut :

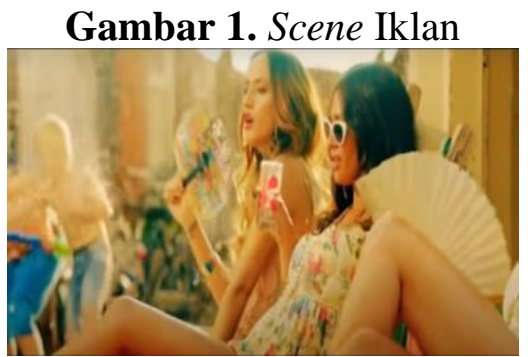

Sumber: Tangkapan Layar pada Video Iklan Hyundai Santa Fe 
Gambar 2. Scene Iklan I

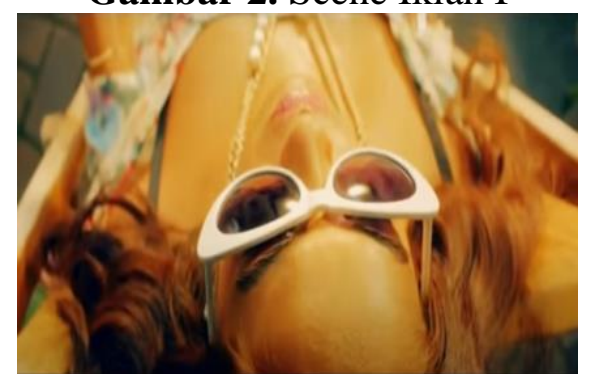

Sumber: Tangkapan Layar pada Video Iklan Hyundai Santa Fe

Pada Gambar 1 dan 2, peneliti menginterpretasikan sosok perempuan yang sensual dan seksi dalam adegan iklan tersebut yang merupakan adegan awal di menit 00:00 - 00:07 dengan pengambilan sudut gambar close up pada wajah dan ekspresi sensual yang menandakan bahwa pemeran adegan tersebut sedang merasakan kepanasan dan kegerahan yang dapat menimbulkan persepsi lain dalam benak pemirsa yang melihat. Pada scene ini berkaitan dengan teori jarum hipodermik yang menjelaskan iklan yang disajikan dalam bentuk video ini memiliki pengaruh besar terhadap pemirsa yang menikmati sajian iklan tersebut dan dapat mengubah sikap atau sudut pandang dalam menginterpretasikan sosok perempuan dalam iklan tersebut, yang berhubungan dengan makna Denotasi dan Konotasi dalam semiotika Roland Barthes, seperti:

1. Makna Denotasi:

Sosok perempuan yang memakai baju mini dan dengan sudut pengambilan gambar secara dekat sehingga menangkap sebagian area tubuh wanita (area paha dan dada wanita tersebut).

2. Makna Konotasi:

Sosok perempuan berpakaian seksi dengan menunjukkan ekspresi sensual terhadap obyek yang dilihatnya dan bagian tubuh yang terekam pada adegan ini mengindikasikan sosok perempuan seksi adalah perempuan yang memperlihatkan sebagian tubuhnya.

Sementara itu pada scene II ini terdapat dalam menit 0:21 - 0:27 yang menampilkan sosok perempuan yang terlihat sangat bergairah dengan mobil Hyundai yang baru saja lewat dengan menimbulkan efek pakaian yang tertiup oleh angin kencang. Ekspresi wajah yang sangat sensual dapat terlihat jelas dimulai dengan tatapan yang seakan - akan mereka sangat bergairah setelah melihat mobil tersebut. Gambar juga menonjolkan bagian-bagian tubuh perempuan secara terbuka.

Gambar 3. Scene Iklan II

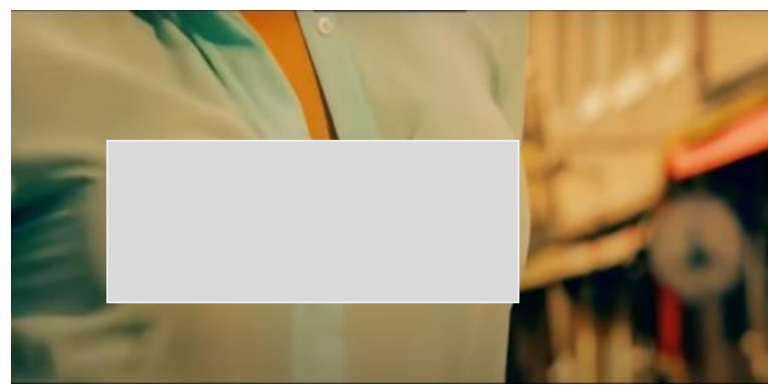

Sumber: Tangkapan Layar pada Video Iklan Hyundai Santa Fe 
Monica Teppy Waworuntu, Ahmad Junaidi: Ekploitasi Tubuh Perempuan dalam Iklan Mobil Hyundai Santa Fe di Youtube

Gambar 4. Scene Iklan II

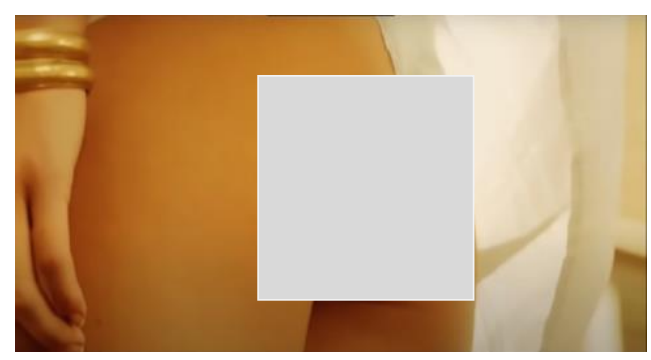

Sumber: Tangkapan Layar pada Video Iklan Hyundai Santa Fe

Dengan sangat jelas terlihat bagian tubuh perempuan tersebut yang terekam pada kamera dengan sudut pengambilan gambar close up, yang menggambarkan bahwa baju dan rok perempuan tersebut tersapu oleh angin kencang karena mobil yang baru saja lewat. Hal yang dapat dimaknai oleh teori semiotika Roland Barthes yaitu :

1. Makna Denotasi:

a. 3 sosok perempuan dengan tatapan bergairah saat melihat sebuah mobil Hyundai Santa Fe tersebut lewat.

b. Bagian tubuh wanita yang terekam kamera secara close up.

2. Makna Konotasi:

a. 3 sosok perempuan yang terlihat memiliki hasrat yang tinggi terhadap suatu objek dengan tatapan penuh gairah yang menggambarkan perempuan tersebut memiliki gairah birahi yang tinggi.

b. Visual dalam scene ini mengobjekkan perempuan kepada hal yang berbau sensualitas dan memunculkan makna bahwa sensualitas perempuan berasal dari tubuh wanita tersebut.

Pada scene lain terdapat dalam menit 0:21 - 0:27 yang menampilkan sosok perempuan yang terlihat sangat bergairah dengan mobil Hyundai yang baru saja lewat dengan menimbulkan efek pakaian yang tertiup oleh angin kencang. Ekspresi wajah yang sangat sensual dimulai dengan tatapan yang seakan-akan mereka sangat bergairah setelah melihat mobil tersebut. Makna Denotasi terdapat 3 sosok perempuan dengan tatapan bergairah saat melihat sebuah mobil Hyundai Santa Fe tersebut lewat. Tiga sosok perempuan yang terlihat memiliki hasrat yang tinggi terhadap suatu objek dengan tatapan penuh gairah yang menggambarkan perempuan tersebut memiliki gairah birahi yang tinggi.

Iklan yang berdurasi 40 detik ini merupakan iklan otomotif yang sempat dilarang tayang di Amsterdam dan India. Di dalam iklan ini terdapat adegan - adegan yang memunculkan makna perempuan sensual terhadap kehadiran perempuan dalam iklan otomotif tersebut, sehingga sosok perempuan dalam iklan ini dijadikan sebuah objek visual yang sensual. Dapat dikatakan sosok perempuan dalam iklan merupakan model eksploitasi fisik dan diskriminasi media melalui penampilan tubuh atau warna kulitnya. Hal utama yang menjadi sorotan dari perempuan dalam sebuah iklan merupakan bagian tubuh dari perempuan yang menjadi skema kapitalisme media untuk memperoleh rating tinggi. Daya tarik seksual mempunyai beberapa peran potensial, yaitu:

1. Materi seksual dalam periklanan bertindak sebagai daya tarik untuk mengambil dan mempertahankan perhatian. 
2. Meningkatkan ingatan terhadap pesan. Iklan yang berisi daya tarik seksual atau simbolisme akan meningkatkan ingatan hanya apabila hal itu cocok dengan kategori produk sesuai dengan pelaksanaan kreatif iklan.

3. Dijalankan oleh isi seksual dalam periklanan adalah untuk membangkitkan tanggapan emosional seperti perasaan arousal (merangsang) atau bahkan nafsu, dengan kebalikannya dapat menimbulkan perasaan negatif seperti rasa jijik, rasa malu, atau perasaan tidak senang.

Berkaitan dengan daya tarik terhadap nafsu yang terdapat dalam iklan Hyundai Santa Fe ini terdapat pada scene II gambar 4.5 dan 4.6. Pada gambar tersebut sosok perempuan atau model dalam iklan menggunakan blus hijau transparan dan rok putih pendek yang memperlihatkan bagian dalaman model iklan tersebut. Scene ini menunjukkan bahwa iklan Hyundai Santa Fe dengan model iklan yang seduktif dianggap dapat menarik perhatian dengan waktu yang lebih lama. Seperti yang dijelaskan oleh Terence A Shimp pada bukunya Periklanan Promosi: Aspek Tambahan Komunikasi Pemasaran Terpadu, bahwa daya tarik seksual ini dapat mempunyai peran yang potensial. Seperti mengundang perhatian mata dan imajinasi bagi para penonton iklan ini.

Dalam jurnal Cultural Masculinity/Femininity Influences on Advertising Appeals memaparkan bahwa efektivitas citra dan daya tarik iklan dapat bervariasi sesuai dengan perbedaan individu (seperti jenis kelamin) atau karakteristik kepribadian (seperti tingkat pemantauan diri) (Snyder dan DeBono, 1985). Oleh karena itu, diasumsikan bahwa latar belakang budaya akan mempengaruhi respon individu terhadap citra dan manfaat iklan, dan pengaruh ini akan dikaitkan dengan perbedaan aksesibilitas konsep laki-laki dan perempuan dalam konstruksi diri. Orang akan berasumsi bahwa mereka mampu melihat apa yang orang lain lihat, setara dengan diri mereka sendiri, mencapai apa yang mereka lihat.

Representasi seorang perempuan dalam sebuah iklan memang sangat berpengaruh dalam sebuah iklan yang dapat menarik perhatian, menurut Frith (2003:223) dalam Wicaksono (2012:149) umumnya kritik terhadap iklan dalam kaitannya dengan representasi perempuan jatuh kepada tiga wilayah yaitu adanya stereotip bahwa perempuan menjadi pemain yang pasif dan kurang kuat di dalam masyarakat, penggambaran perempuan sebagai objek seksual dalam iklan, dan efek kumulatif dari penggambaran tentang harga diri perempuan.

Sebuah strategi yang digunakan bagi pengiklan untuk mempromosikan sebuah produk atau jasa melalui iklan dengan menampilkan sosok perempuan dianggap sebagai ide kreatif untuk menarik perhatian para penonton iklan agar penonton dapat mengingat dan bertahan lebih lama untuk menonton iklan yang ditampilkan. Seakan dengan secara sengaja iklan tersebut menampilkan sosok atau citra seorang perempuan tersebut dengan menyisipkan sisi seksualitas perempuan yang dapat mempengaruhi bawah sadar audiens, hal ini berkaitan dengan pesan subliminal sebagai pesan yang tidak ditampilkan secara langsung namun mempersuasi alam bawah sadar penerima pesan (Liliweri, 2011:574 dalam Wicaksono, 2012).

Melalui pesan ini dapat terlihat dalam scene iklan Hyundai Santa Fe yang menunjukkan para perempuan dalam iklan tersebut diproyeksikan sangat seksi dan sensual, yang dimulai dari sudut pengambilan gambar, ekspresi wajah, dan beberapa tanda yang dapat dimaknai sebagai lust. Lust, menurut Cambridge Dictionary mempunyai arti yaitu a very strong sexual desire yang jika diartikan ke dalam bahasa Indonesia adalah keinginan seksual yang sangat kuat yang dapat terlihat dalam setiap scene dalam iklan Hyundai Santa Fe tersebut. Iklan subliminal adalah suatu teknik 
Monica Teppy Waworuntu, Ahmad Junaidi: Ekploitasi Tubuh Perempuan dalam Iklan Mobil Hyundai Santa Fe di Youtube

periklanan yang sekilas menyampaikan suatu pesan dengan begitu cepat, sehingga tidak dipersepsikan dengan sadar, tapi tinggal di bawah ambang kesadaran, sehingga konsumen yang melihat iklan tersebut akan secara tidak sadar menuruti pesan iklan yang disampaikan secara cepat tersebut.

Pada gambar-gambar yang terdapat dalam iklan Hyundai Santa Fe ini, semakin memperkuat kesan ekplotasi tubuh perempuan dari pengambaran sensualitas dari masing - masing pemeran sosok perempuan dalam iklan. Penggambaran sensualitas perempuan ini terlihat akibat pakaian yang terlalu tipis dan sibakkan angin yang mengenai rok yang memperlihatkan bagian payudara dan bokong perempuan tersebut. Dalam konteks ini sensualitas perempuan tercipta melalui adanya bagian - bagian tubuh yang terekspos. Berkaitan dengan hal tersebut, eksploitasi mengenai representasi perempuan yang seharusnya tidak digambarkan demikian menjadi penanda yang menimbulkan persepsi bahwa perempuan sangatlah seksi jika menunjukkan bagian-bagian tertentu dari tubuhnya. Secara tidak sadar pesan subliminal tersebut tergambarkan dalam iklan Hyundai Santa Fe ini.

Penggunaan teknik pengambilan gambar yang secara dekat atau close up dapat memberikan kesan yang intim kepada audiens terhadap sosok perempuan tersebut, yang dapat mengikat emosi dan imajinasi dengan objek yang ada pada saat audiens melihat dan menonton iklan tersebut secara lebih dekat. Dalam hal ini, sensualitas tergambar melalui pengambilan gambar pada iklan yang menyasar pada bagian tubuh tertentu pada sosok pemeran perempuan tersebut.

Dalam buku Definitive Book of Body Language dijelaskan bahwa ekspresi wajah dengan sedikit memejamkan mata, menaikkan alis, dan dengan bibir yang sedikit terbuka merujuk pada ekspresi sensual perempuan (Pease dan Pease 2006:174). Salah satu adegan yang berkaitan dengan hal ini terdapat pada gambar 4.4, ekspresi wajah yang ditampilkan sesuai dengan terjemahan yang disampaikan pada buku tersebut. Pose - pose dengan ekspresi wajah yang demikian kerap muncul dalam iklan ini seperti yang terdapat pada cuplikan gambar 2, salah satu sosok perempuan yang mempunyai ekspresi wajah yang sama yang terkesan sensual. Ekspresi wajah dari para sosok perempuan pada iklan Hyundai Santa Fe ini tak lepas dari ketertarikannya pada mobil Hyundai Santa Fe yang lewat di depan mereka. Hal tersebut menunjukkan para sosok perempuan tersebut terlihat mempunyai hasrat yang tinggi terhadap mobil Hyundai Santa Fe tersebut. Kesan sensual ini dihadirkan dengan maksud jika seseorang memiliki mobil ini maka dapat memikat wanita dengan mudah.

Penggambaran perempuan dalam iklan Hyundai Santa Fe ini dapat dikatakan tidak tepat dengan maksud dari iklan produk yang ditampilkan. Dengan bermaksud mengiklankan sebuah mobil jenis baru dengan menggunakan model perempuan sebagai pemanis dalam iklan tersebut agar banyak peminat yang melirik mobil ini, akan tetapi representasi perempuan yang terdapat di dalam iklan ini dapat disalah artikan bagi audiens yang menonton iklan tersebut. Bagian - bagian tubuh tertentu yang terdapat dalam beberapa scene iklan tersebut dapat dinilai memiliki nilai sensual dan erotis yang mengesploitasi tubuh dan dapat merugikan seorang perempuan. Hal tersebut menjadi sebuah konsumsi publik yang seharusnya tidak ditampilkan bersamaan dengan produk iklan tersebut.

\section{Simpulan}

Iklan Hyundai Santa Fe memberikan gambaran tentang sebuah iklan otomotif yang cenderung ekploitsatif dengan menggambarkan stereotip tubuh perempuan 
dalam mempromosikan suatu jenis mobil terbaru dari merek Hyundai. Penggambaran sosok perempuan dalam iklan Hyundai Santa Fe adalah sosok perempuan yang menampilkan kesensualitasannya dan keseksiannya dalam ketertarikannya dengan sebuah mobil. Terdapat tanda - tanda tersembunyi di dalam iklan tersebut, yaitu ekspresi wajah perempuan yang melambangkan gairah dan dapat disalah artikan dengan arti untuk menarik lawan jenis dengan rupa menggoda dengan ekspresi wajah demikian.

\section{Ucapan Terima Kasih}

Penulis mengucapkan banyak terima kasih kepada semua pihak yang mendukung dan membimbing dalam proses penulisan penelitian ini, khususnya kepada Fakultas Ilmu Komunikasi Universitas Tarumanagara.

\section{Daftar Pustaka}

Anggito, A., \& Setiawan, J. (2018). Metodologi penelitian kualitatif. CV Jejak (Jejak Publisher).

Chang, C. (2006). Cultural Masculinity/Femininity Influences on Advertising Appeals. Journal of Advertising Research. 46(3), pp.315-323.

Hasanah, H. (2017). Teknik-teknik observasi (sebuah alternatif metode pengumpulan data kualitatif ilmu-ilmu sosial). At-Taqaddum, 8(1), 21-46.

Kotler, Philip, Alan R. Andreasen. (1991). Strategic Marketing for Nonprofit Organizations.Prentice Hall, New Jersey, USA.

Moleong, Lexy J. (2013). Metode Penelitian Kualitatif. PT. Remaja Rosdakarya. Bandung.

Marifah, N. (2020). Representasi Perempuan dalam Novel Aroma Karsa Karya Dee Lestari: Kajian Semiotika Roland Barthes. Jurnal Sapala 6(1).

Pratiwi, T., Putri, Y., \& Sugandi, M. (2015). Analisis Semiotika Roland Barthes terhadap logo Calais Tea. Diakses dari https://core.ac.uk/download/pdf/299904072.pdf

Rahmawati, R. L. (2020). Pengaruh Terpaan Pesan Iklan Zilingo Versi Siapa Sih Lo di Youtube Terhadap Kesadaran Merek Konsumen (Studi pada Mahasiswa Ilmu Komunikasi Universitas Muhammadiyah Malang Angkatan 2016). Master's thesis, Universitas Muhammadiyah Malang 2020. (pp. 13-16). Diakses dari Http://eprints.umm.ac.id/58633/.

Susanto, E, H. (2014). Dinamika Pesan Iklan. Jurnal Komunikasi Universitas Tarumanagara Tahun VI/02/2014. https://journal.untar.ac.id/index.php/komunikasi/article/view/28.

Wicaksono, I. P. (2012). Representasi Eksploitasi Perempuan dalam Iklan. 